\title{
Genetic variability in Chilean pepino (Solanum muricatum Aiton) fruit
}

\author{
Carlos Muñoz ${ }^{*}$, Ricardo Pertuzé1, Mónica Balzarini², Cecilia Bruno² ${ }^{\text {, and Angélica Salvatierra }}{ }^{3}$
}

\begin{abstract}
Solanum muricatum Aiton is an herbaceous perennial fruit species native to the Andean region of Colombia, Ecuador, and Peru. In Chile, it was probably introduced in pre-Columbian times as a domesticated species and is presently grown in the coastal areas of the north-central regions of Coquimbo and Valparaíso. The species has been bred, but little information is available on its genetic variability in Chile. To characterize the genetic variability in this species, fruits were collected from 14 different ecotypes and seeds were sown to generate approximately 60 segregants from each accession. Segregants were planted at two different locations to characterize their fruits and fruiting habits. Fruit weight ranged from 30 to 485 $\mathrm{g}$, while length was 3.5 to $16.7 \mathrm{~cm}$, equatorial diameter 3.4 to $9.5 \mathrm{~cm}$, pulp firmness 1.7 to $10 \mathrm{~N}$, and soluble solids content 6.3 to $13.5^{\circ}$ Brix. Fruit shape ranged from flat to oblong. When analyzing the estimated variance components with a mixed linear model, most of the variability between different ecotypes was in fruit shape, length, and weight, which resulted in a genetic contribution of $34.6 \%, 29.3 \%$, and $18.1 \%$ of the total variability of these traits, respectively. Genetic variability was also found for pulp firmness and soluble solids content. Therefore, enough variability is available in seed-propagated pepinos from Chilean ecotypes to allow genetic improvement of these fruit quality traits. There was also variability from genotype $\times$ environment interactions; therefore, selections must be performed for specific environments or stable selections must be found.
\end{abstract}

Key words: Ecotypes, mixed linear models, principal component analysis.

\section{INTRODUCTION}

Pepino (Solanum muricatum Aiton) is an herbaceous perennial that produces a round to oblong edible fruit with a yellowish skin that often has light to intense purple stripes. The flesh is yellowish-green to pink with a juicy melon-like texture and subtle flavor and aroma. The plant is native to the Andean regions of Colombia, Ecuador, and Peru where it is also cultivated and consumed (Heiser, 1964). In Chile, it was probably introduced by the Incas and is presently cultivated in the coastal areas of the Coquimbo and Valparaíso Regions. Domestication of this species, including its agamic propagation, occurred in pre-Columbian times together with other Solanaceous species (National Research Council, 1989); however, the pepino never was as important as tomatoes or potatoes. In recent years, there has been renewed interest in this species in countries such as Turkey, Spain, New Zealand, and The Netherlands (Rodríguez-Burruezo et al., 2011).

\footnotetext{
${ }^{1}$ Universidad de Chile, Facultad de Ciencias Agronómicas, Casilla Correo 1004, Santiago, Chile.

"Corresponding author (carlosmunozschick@u.uchile.cl).

${ }^{2}$ Universidad Nacional de Córdoba, Facultad de Ciencias Agropecuarias, Casilla Correo 509, Córdoba, Argentina.

${ }^{3}$ Instituto de Investigaciones Agropecuarias, INIA Intihuasi, Casilla Correo 36-B, La Serena, Chile.

Received: 29 August 2013.

Accepted: 5 March 2014.
}

doi:10.4067/S0718-58392014000200003
In some of these countries, breeding programs have been started to develop new varieties adapted to different environments, including greenhouses (Prohens and Nuez, 1999; Cavusoglu and Sulusoglu, 2013). The existence of genetic variability is a must for developing effective breeding programs. However, studies on the genetic variability of this species are scarce (Cavusoglu et al., 2009) and no studies are available about the variability of the fruit. To contribute to the knowledge of genetic variability in pepino fruit in Chile, a segregant population obtained from local ecotypes was studied.

\section{MATERIALS AND METHODS}

Segregant populations were obtained from ecotypes found at different locations throughout the area cultivated with pepino in Chile and named A to O (Table 1). Ripe fruit was collected from each selected genotype and seed was cleaned, dried, and stored at room temperature. For germination, seeds were soaked in distilled water for 48 $\mathrm{h}$, treated with $400 \mathrm{mg} \cdot \mathrm{L}^{-1}$ gibberellic acid for $24 \mathrm{~h}$, and immediately sown in polyurethane speedlings. From $20 \%$ to $40 \%$ of the seeds germinated and generated variable amounts of plantlets (Table 1).

In August 2001, when plants were 3-mo-old, they were randomly planted in an experimental plot at a density of 15625 plants ha ${ }^{-1}(0.8 \mathrm{~cm} \times 0.8 \mathrm{~cm})$ at two locations, Cerrillos de Tamaya (30 $34^{\prime}$ S; $71^{\circ} 25^{\prime}$ ' W; $251 \mathrm{~m}$ a.s.l.) and Pan de Azúcar (3001' S; $71^{\circ} 15^{\prime}$ W; 113 m a.s.1.) in 
the Coquimbo Region, Chile. The climate at these two locations is shown in Table 2.

Soils were similar at both locations and were of granite origin with sandy texture and low waterholding capacity. A drip irrigation system was used and irrigation scheduling was based on pan evaporation. Standard cultural practices for pepino growing were used throughout the experiment. A yellow background skin color was used as the maturity index at harvest, which started 6 mo after planting. The following fruit characteristics were measured by the standard procedures to characterize fruits (Table 4): background and coverage color, fruit set, productivity, weight, length, diameter, pulp pressure, soluble solids content, flesh color, texture, taste, and number of flowers per cluster. To estimate potential plant productivity, the number of flower clusters per plant and number of flowers per inflorescence were determined. The mean value was obtained for continuous traits and the median for qualitative traits. Variance components or quantitative characters were estimated by a mixed linear model to evaluate the effect of genotype (combination of segregating fruit and ecotype), locality, and interaction of genotype by location. The following mixed linear model was used:

$$
\mathrm{E}\left(\mathrm{y}_{\mathrm{ij}}\right)=\mu+\mathrm{G}_{\mathrm{i}}+\mathrm{E}_{\mathrm{j}}+\mathrm{G} \times \mathrm{E}_{\mathrm{ij}}
$$

where $\mathrm{E}\left(\mathrm{y}_{\mathrm{ij}}\right)$ is the expected value for the morphological character for the $\mathrm{i}$-th genotype in the $\mathrm{j}$-th locality, $\mathrm{G}_{\mathrm{i}}$ is the effect of the $\mathrm{i}-t h$ genotype, $E_{j}$ the effect of the $j$-th location, and $\mathrm{G} \times \mathrm{E}_{\mathrm{ij}}$ is the effect of the genotype $\times$ location interaction. Genotype was considered as a random effect, whereas location was considered as a fixed effect. The matrix of variances and covariances of the random effects

Table 1. Number of segregants obtained from each ecotype.

\begin{tabular}{lc}
\hline Ecotype & Number of segregants \\
\hline A & 59 \\
B & 72 \\
C & 64 \\
D & 53 \\
E & 50 \\
F & 47 \\
G & 73 \\
H & 61 \\
I & 102 \\
J & 64 \\
K & 53 \\
M & 76 \\
N & 65 \\
O & 64 \\
\hline
\end{tabular}

Table 2. Main climatic data for locations where pepino segregants were evaluated.

\begin{tabular}{lcc}
\hline & \multicolumn{2}{c}{ Location } \\
\cline { 2 - 3 } Climatic parameter & $\begin{array}{c}\text { Cerrillos de } \\
\text { Tamaya }\end{array}$ & $\begin{array}{c}\text { Pan de } \\
\text { Azúcar }\end{array}$ \\
\hline Mean temperature, ${ }^{\circ} \mathrm{C}$ & 16.6 & 13.5 \\
Average maximum temperature, ${ }^{\circ} \mathrm{C}$ & 24.9 & 20.0 \\
Average minimum temperature, ${ }^{\circ} \mathrm{C}$ & 6.3 & 7.0 \\
Degree-days, $5^{\circ} \mathrm{C}$ base temperature & 4220 & 3106 \\
Frost-free period, mo & 10 & 12 \\
Annual rainfall, $\mathrm{mm}$ & 126 & 104 \\
Pan evaporation, $\mathrm{mm}$ & 1676 & 1220 \\
\hline
\end{tabular}

(G) was estimated by the Restricted Maximum Likelihood (REML) algorithm with a model of variance components using the SAS 9.3 PROC MIXED procedure. Normality and homoscedasticity were checked by Shapiro Wilks and Levene residual analysis, respectively. Variance component estimates from REML were used to calculate broad sense heritability for each morphological variable using the formula proposed by Nyquist (1991).

A multivariate distance matrix was estimated among all genotype pairs for each location by Gower's distance. A hierarchical analysis of variance (AMOVA) (Excoffier et al., 1992) based on the distance matrix allowed the estimation the genetic variability between locations, between ecotypes among each location and between segregants among each ecotype. A cluster analysis using Gower's distance and Ward's clustering algorithm was implemented to categorize ecotypes according to their multivariate genetic similarity/difference. To visually represent variability among ecotypes we used principal component analysis (PCA) that included all the quantitative variables. Info-Gen software (Balzarini and Di Rienzo, 2013) was used for multivariate analyses.

\section{RESULTS AND DISCUSSION}

High variability was observed for all the measured continuous variables of fruits, regardless of the ecotype that originated the segregant (Table 3). For fruit weight, values ranged from 30 to $485 \mathrm{~g}$, length 3.5 to $16.7 \mathrm{~cm}$, equatorial diameter 3.4 to $9.5 \mathrm{~cm}$, pulp firmness 1.7 to $10.0 \mathrm{~N}$, and soluble solids content 6.3 to $13.5^{\circ}$ Brix. Fruit shape varied from flat (shape values $<1$ ), round (shape values $=1$ ), and oblong (shape values $>1$ ).

Less variability was detected for qualitative traits (Table 4). In this case, four out of eight characters did not show any variability. Continuous characters usually show more variability because they are more prone to genotype $x$ environment interactions than qualitative traits, which are less affected by these interactions (Falconer, 1990; Falconer and MacKay, 1996). On the other hand, under commercial conditions, pepino is vegetatively propagated mainly through cuttings because it is not true to type when seed-propagated due to its high heterozygosity (Prohens and Nuez, 1999). The reason for its high heterozygosity is not well understood because the species is normally self-pollinated, but it can also cross-pollinate and it can often be a facultative parthenocarpic species (Kowalczyk, 2008).

When analyzing the estimated variance components with a mixed linear model, most of the variability between the different ecotypes was in fruit shape, length, and weight, which resulted in a $34.6 \%, 29.3 \%$, and $18.1 \%$ heritability contribution, respectively (Table 5). AMOVA results suggest that $93 \%$ of total genetic variability among evaluated ecotypes can be attributed to segregants of each ecotype. Few genetic differences between ecotypes 
Table 3. Mean, minimum, and maximum values of continuous variables of pepino fruits produced by segregants from different Chilean ecotypes. Minimum and maximum values are in parenthesis.

\begin{tabular}{|c|c|c|c|c|c|c|c|}
\hline Ecotype & $\begin{array}{l}\text { Number of } \\
\text { segregants }\end{array}$ & Weight & Length & $\begin{array}{c}\text { Equatorial } \\
\text { diameter }\end{array}$ & $\begin{array}{c}\text { Shape } \\
\text { (length/equatorial } \\
\text { diameter) }\end{array}$ & Pulp firmness & $\begin{array}{l}\text { Soluble solid } \\
\text { content }\end{array}$ \\
\hline & & $\mathrm{g}$ & $-\mathrm{cm}$ & & & Newton & ${ }^{\circ}$ Brix \\
\hline A & 59 & $142.5(38-465)$ & $8.3(4.6-12.8)$ & $5.9(4.1-9.5)$ & $1.4(0.8-2.5)$ & $16.9(8.9-28.0)$ & $9.6(7.5-12.8)$ \\
\hline B & 72 & $131.7(33-295)$ & $8.2(5.3-12.5)$ & $5.7(3.4-8.9)$ & $1.5(0.9-2.3)$ & $19.1(8.0-33.4)$ & $9.8(7.3-13.3)$ \\
\hline $\mathrm{C}$ & 64 & $130.2(39-301)$ & $8.3(5.0-11.7)$ & $5.7(3.4-8.0)$ & $1.5(0.9-2.5)$ & $18.7(8.9-31.1)$ & $9.9(7.0-12.8)$ \\
\hline $\mathrm{D}$ & 53 & $138.2(45-286)$ & $8.3(5.2-11.9)$ & $5.9(3.5-9.1)$ & $1.4(0.9-2.2)$ & $17.8(8.9-33.4)$ & $9.6(7.0-12.0)$ \\
\hline $\mathrm{E}$ & 50 & $133.0(42-309)$ & $8.0(4.9-11.5)$ & $5.8(3.8-7.9)$ & $1.4(0.9-2.8)$ & $19.6(10.2-44.5)$ & $9.7(7.7-13.0)$ \\
\hline $\mathrm{F}$ & 47 & $140.2(49-485)$ & $8.4(5.7-16.7)$ & $5.8(4.1-8.1)$ & $1.5(1.0-2.2)$ & $18.7(11.1-30.2)$ & $9.8(7.9-13.3)$ \\
\hline G & 73 & $127.1(30-272)$ & $8.2(3.5-12.6)$ & $5.7(3.9-7.6)$ & $1.5(0.8-2.7)$ & $19.6(8.9-41.4)$ & $9.8(6.3-12.0)$ \\
\hline $\mathrm{H}$ & 61 & $149.7(56-364)$ & $8.3(3.9-11.8)$ & $6.1(4.2-8.9)$ & $1.4(0.7-2.7)$ & $17.8(10.2-40.0)$ & $9.8(7.0-13.5)$ \\
\hline I & 102 & $136.9(59-286)$ & $8.4(4.5-13.2)$ & $5.8(4.2-8.0)$ & $1.5(0.8-2.8)$ & $17.8(6.7-35.6)$ & $10.0(7.2-13.2)$ \\
\hline $\mathrm{J}$ & 64 & $129.1(44-439)$ & $7.7(4.6-10.7)$ & $5.7(3.8-9.3)$ & $1.4(0.8-2.2)$ & $16.9(8.9-24.5)$ & $10.0(7.3-12.5)$ \\
\hline K & 53 & $134.2(72-271)$ & $8.3(6.2-11.5)$ & $5.8(4.3-7.9)$ & $1.5(0.9-2.2)$ & $18.2(8.9-28.9)$ & $10.0(6.5-13.3)$ \\
\hline M & 76 & $135.7(54-349)$ & $8.2(4.9-12.4)$ & $5.8(4.0-9.1)$ & $1.4(0.9-2.4)$ & $17.8(8.9-44.5)$ & $9.7(4.0-12.8)$ \\
\hline $\mathrm{N}$ & 65 & $127.6(41-223)$ & $8.2(5.0-12.9)$ & $5.6(3.8-7.5)$ & $1.5(0.9-2.3)$ & $17.8(8.9-35.6)$ & $10.1(7.0-13.0)$ \\
\hline $\mathrm{O}$ & 64 & $127.7(46-256)$ & $8.1(4.9-12.0)$ & $5.6(3.5-7.4)$ & $1.5(0.9-2.8)$ & $19.6(7.6-40.0)$ & $10.0(7.0-13.0)$ \\
\hline
\end{tabular}

Table 4. Median values of qualitative variables of pepino fruits produced by segregants from different Chilean ecotypes.

\begin{tabular}{|c|c|c|c|c|c|c|c|c|}
\hline Ecotype & Productivity $^{1}$ & $\begin{array}{l}\text { Flesh } \\
\text { color }^{2}\end{array}$ & $\begin{array}{l}\text { Ability of fruit } \\
\text { set (curdles) }\end{array}$ & $\begin{array}{l}\text { Coverage } \\
\text { color }^{4}\end{array}$ & $\begin{array}{c}\text { Background } \\
\text { color }^{5}\end{array}$ & $\begin{array}{l}\text { Flesh } \\
\text { taste }^{6}\end{array}$ & $\begin{array}{l}\text { Number of flower } \\
\text { clusters per plant }\end{array}$ & Texture $^{7}$ \\
\hline A & 2.0 & 6.0 & 1.5 & 3.0 & 3.0 & 2.0 & 2.0 & 2.0 \\
\hline B & 2.0 & 6.0 & 1.5 & 3.0 & 3.0 & 3.0 & 2.5 & 2.0 \\
\hline $\mathrm{C}$ & 3.0 & 6.0 & 1.5 & 3.0 & 3.0 & 2.0 & 3.0 & 2.0 \\
\hline $\mathrm{D}$ & 2.0 & 7.0 & 1.5 & 3.0 & 3.0 & 2.0 & 2.0 & 2.0 \\
\hline E & 2.5 & 7.0 & 1.5 & 3.0 & 3.0 & 3.0 & 2.0 & 2.0 \\
\hline $\mathrm{F}$ & 2.0 & 7.0 & 1.5 & 3.0 & 3.0 & 2.0 & 3.0 & 2.0 \\
\hline G & 2.0 & 7.0 & 1.5 & 3.0 & 3.0 & 2.0 & 2.0 & 2.0 \\
\hline $\mathrm{H}$ & 3.0 & 7.0 & 1.5 & 3.0 & 3.0 & 2.5 & 2.0 & 2.0 \\
\hline I & 2.0 & 7.0 & 1.5 & 3.0 & 3.0 & 3.0 & 2.0 & 2.0 \\
\hline $\mathrm{J}$ & 2.0 & 7.0 & 1.5 & 3.0 & 3.0 & 2.0 & 2.5 & 2.0 \\
\hline $\mathrm{K}$ & 3.0 & 7.0 & 1.5 & 3.0 & 3.0 & 2.0 & 3.0 & 2.0 \\
\hline M & 2.0 & 7.0 & 1.5 & 3.0 & 3.0 & 2.0 & 2.0 & 2.0 \\
\hline $\mathrm{N}$ & 2.0 & 6.0 & 1.5 & 3.0 & 3.0 & 3.0 & 2.0 & 2.0 \\
\hline $\mathrm{O}$ & 2.0 & 7.0 & 1.5 & 3.0 & 3.0 & 2.0 & 2.0 & 2.0 \\
\hline
\end{tabular}

${ }^{1}$ Productivity: $1=<5$ fruits per plant; $2=5-10 ; 3=>10$.

${ }^{2}$ Flesh color: 1 = greenish; 7 = intense yellow.

${ }^{3}$ Curdless: number of fruits per cluster.

${ }^{4}$ Coverage color: 1 = no dark stripes; $2=$ few narrow dark stripes; 3 = few wide dark stripes; $4=$ abundant wide dark stripes.

${ }^{5}$ Background color: 1 = greenish; 2 = pale yellow; 3 = intense yellow.

${ }^{6}$ Flesh taste: 3 = excellent; 2 = medium; 1 = poor.

${ }^{7}$ Texture: 1 = crunchy; 2 = intermediate; $3=$ mealy.

evaluated at each location were detected and accounted for less than $1 \%$ of total variability. Principal component analysis over the correlation matrix was performed for each of the environments to evaluate the variability of the 14 ecotypes (Figures 1 and 2). Results showed that principal components (PC) 1 and 2 explained $48.7 \%$ of total variability in Cerrillos de Tamaya and 50.5\% in Pan de Azúcar. In Cerrillos de Tamaya (Figure 1), variables such as fruit diameter, weight, soluble solids, and pulp pressure were the most decisive in $\mathrm{PC} 1$ by differentiating the $\mathrm{H}, \mathrm{D}$, and $\mathrm{A}$ ecotypes from $\mathrm{O}, \mathrm{B}$, and N. Ecotypes located on the right in Figure 1 showed greater fruit diameter and weight, but less pulp pressure and soluble solids. PC1 separated productivity variables such as fruit weight, diameter, and length from quality variables such as soluble solids, pulp firmness, and shape. PC2 differentiates ecotypes $\mathrm{K}$ and $\mathrm{O}$ from $\mathrm{J}$ and $\mathrm{B}$. The first two showed more background color, productivity, and shape but a lower cluster number. At the Pan de Azúcar location (Figure 2), PC1 also separated ecotypes according to longer and heavier fruits and more productive plants, such as ecotypes $\mathrm{F}$ and $\mathrm{A}$, from others with more soluble solids, pulp pressure, and number of fruits, such as ecotypes $\mathrm{J}$, $\mathrm{K}, \mathrm{D}, \mathrm{C}$, and I. The cluster analysis performed on all the morphological fruit traits showed larger differences between localities than between ecotypes (Figure 3), but morphological variability among genotypes was enough to differentiate them.

It is interesting to mention that Denton and Nwangburuka (2011) found similar results working with Solanum anguivi Lam., another non-tuberous

Table 5. Pepino continuous character means, total variability as standard deviation, and genotype variability as percentage of total observed variability.

\begin{tabular}{lrcc}
\hline Trait & Mean & Total variability & Heritability \\
\hline & & SD & $\%$ \\
Length, cm & 8.2 & 1.7 & 29.3 \\
Shape & 1.5 & 0.3 & 34.6 \\
Weight, g & 134.4 & 53.3 & 18.1 \\
Pulp firmness, N & 4.1 & 1.2 & 7.2 \\
Soluble solids, ${ }^{\circ}$ Brix & 9.8 & 1.3 & 7.3 \\
Diameter, cm & 5.8 & 0.9 & 15.7 \\
\hline
\end{tabular}




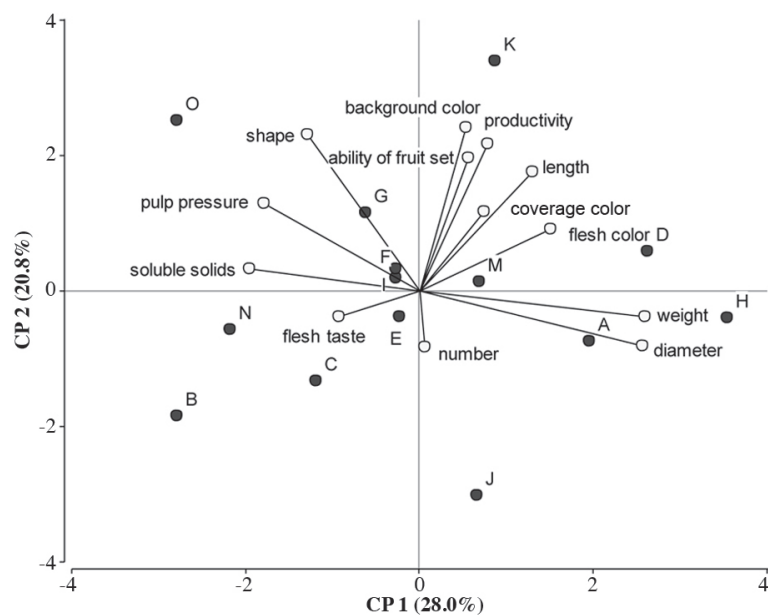

Figure 1. Principal component analysis biplot of 14 ecotypes of pepino evaluated in Cerrillos de Tamaya (Chile). Blue dots represent ecotypes and vectors with yellow dots represent evaluated variables.

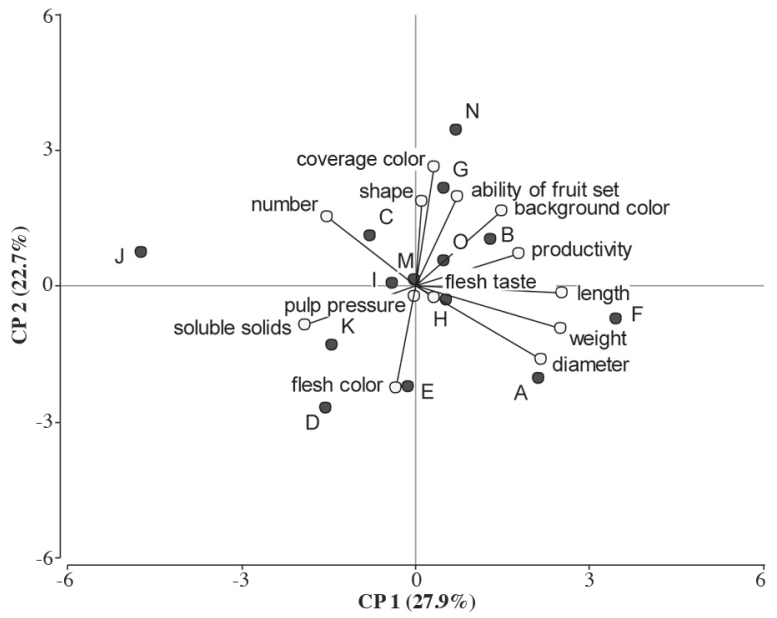

Figure 2. Principal component analysis Biplot of 14 ecotypes of pepino evaluated in Pan de Azúcar (Chile). Blue dots represent ecotypes and vectors with yellow dots represent evaluated variables.

domesticated Solanaceae from non-arid areas of Africa. They found that fruit width and total weight accounted for an important part of the variability in their first PC and revealed that most of the selection and diversity is concentrated in the shape and size of the fruit, that is, for its diameter, length, or weight. More domestication and selection might have been differentiated from those characters.

In PCA, for each of the evaluated environments, more variability was observed in Pan de Azúcar ecotypes than in those from Cerrillos de Tamaya. Ecotypes from Cerrillos de Tamaya such as $\mathrm{H}$ and A showed more productive plants and fruits with better taste, greater width and weight, but poor color. In this same environment, ecotypes such as $\mathrm{O}$, $\mathrm{B}$, and $\mathrm{N}$ showed more soluble solids, pulp pressure, and better fruit shape. Pan de Azúcar ecotypes with better fruit aptitudes were A, F, and B due to their higher productivity, better diameter, length, and weight (Figure 1).

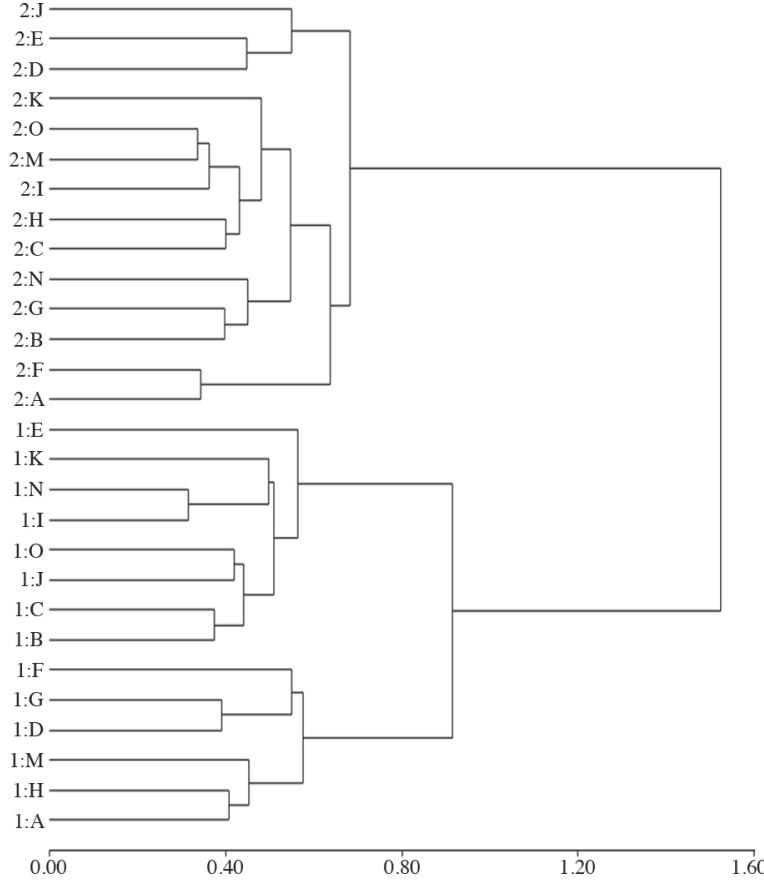

Figure 3. Dendrogram from cluster analysis with distance based on Gower's similarity index (SG). The transformation from similarity index to distance measure was (1-SG)1/2. Ward's cluster algorithm was used.

It is possible to find enough variability for potential breeding programs, and variability could be exploited through hybridizations among these pepino ecotypes. Such variability has also been reported in other Solanaceae landraces or ecotypes as described by Gunjeet et al. (2008) in Indian eggplant landraces or among wild tomato relatives such as those analyzed by Albrecht et al. (2010).

Only two location ecotypes were collected in this study and they have already shown interesting variability. There is more variability in Chile and other Andean countries where it is being cultivated. Improvements with selections can be done efficiently. In the case of pepino, once good selections are obtained they can be clonally propagated even though some problems with diseases might be present and should be overcome.

\section{CONCLUSIONS}

Enough variability is available in seed-propagated pepinos from Chilean ecotypes to allow the genetic improvement of this species regarding fruit size, shape, pulp firmness, sugar content, and other important fruit quality components. Other traits exhibit less variability; therefore, genetic gain will be less if these characters are to be improved. There is also variability resulting from genotype $\times$ environment interactions; therefore, selections must be performed for specific environments or stable selections must be found. 


\section{LITERATURE CITED}

Albrecht, E., M. Escobar, and R.T. Chetelat. 2010. Genetic diversity and population structure in the tomato-like nightshades Solanum lycopersicoides and S. sitiens. Annals of Botany 105:535-554.

Balzarini M.G., y J.A. Di Rienzo. 2013. InfoGen, software estadístico para análisis de datos genéticos. Facultad de Ciencias Agropecuarias, Universidad Nacional de Córdoba, Córdoba, Argentina.

Cavusoglu, A., E.I. Erkel, and M. Sulusoglu. 2009. The effect of climatic factors at different growth periods on pepino (Solanum muricatum Aiton) fruit quality and yield. Journal of Food Agriculture Environment 7:551-554.

Cavusoglu, A., and M. Sulusoglu. 2013. In vitro propagation and acclimatization of pepino (Solanum muricatum). Journal of Food Agriculture Environment 11:410-415.

Denton, O.A., and C.C. Nwangburuka. 2011. Genetic variability in eighteen cultivars of Solanum anguivi Lam. using principal component analysis (PCA) and single linkage cluster analysis (SLCA). Annals of Biological Research 2(4):62-67.

Excoffier, L., P. Smouse, and J. Quattro. 1992. Analysis of molecular variance inferred from metric distances among DNA haplotypes: Application to human mitochondrial DNA restriction data. Genetics 131:479-491.

Gunjeet, K., B.L. Meena, R. Kar, S.K. Tiwari, K.K. Gangopadhyay, I.S. Bisht, et al. 2008. Morphological diversity in brinjal (Solanum melongena L.) germplasm accessions. Plant Genetic Resources $6(3): 232-236$
Falconer, D.S. 1990. Selection in different environments: effects on environmental sensitivity (reaction norm) and on mean performance. Genetics Research 56:57-70.

Falconer, D.S., and T.F.C. MacKay. 1996. Introduction to quantitative genetics. 464 p. $4^{\text {th }}$ ed. Longman, New York, USA.

Kowalczyk, K. 2008. The kind of pollination and ability to parthenocarpy of pepino (Solanum muricatum Ait.) Folia Horticulturae 20:23-29.

Heiser, C.B. 1964. Origin and variability of the pepino (Solanum muricatum): A preliminary report. Baileya 12:151-158.

National Research Council. 1989. Lost crops of the Incas: Littleknown plants of the Andes with promise for worldwide cultivation. National Academy Press, Washington D.C., USA.

Nyquist, W.E. 1991. Estimation of heritability and prediction of selection response in plant populations. Critical Reviews in Plant Sciences 10:235-322.

Prohens, J., and F. Nuez. 1999. Strategies for breeding a new greenhouse crop, the pepino (Solanum muricatum Aiton). Canadian Journal of Plant Science 79:269-275.

Rodríguez-Burruezo, A., J. Prohens, and A.M. Fita. 2011. Breeding strategies for improving the performance and fruit quality of the pepino (Solanum muricatum): A model for the enhancement of underutilized exotic fruits. Food Research International 44:19271935 . 